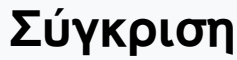

Tóp. 26 (2016)

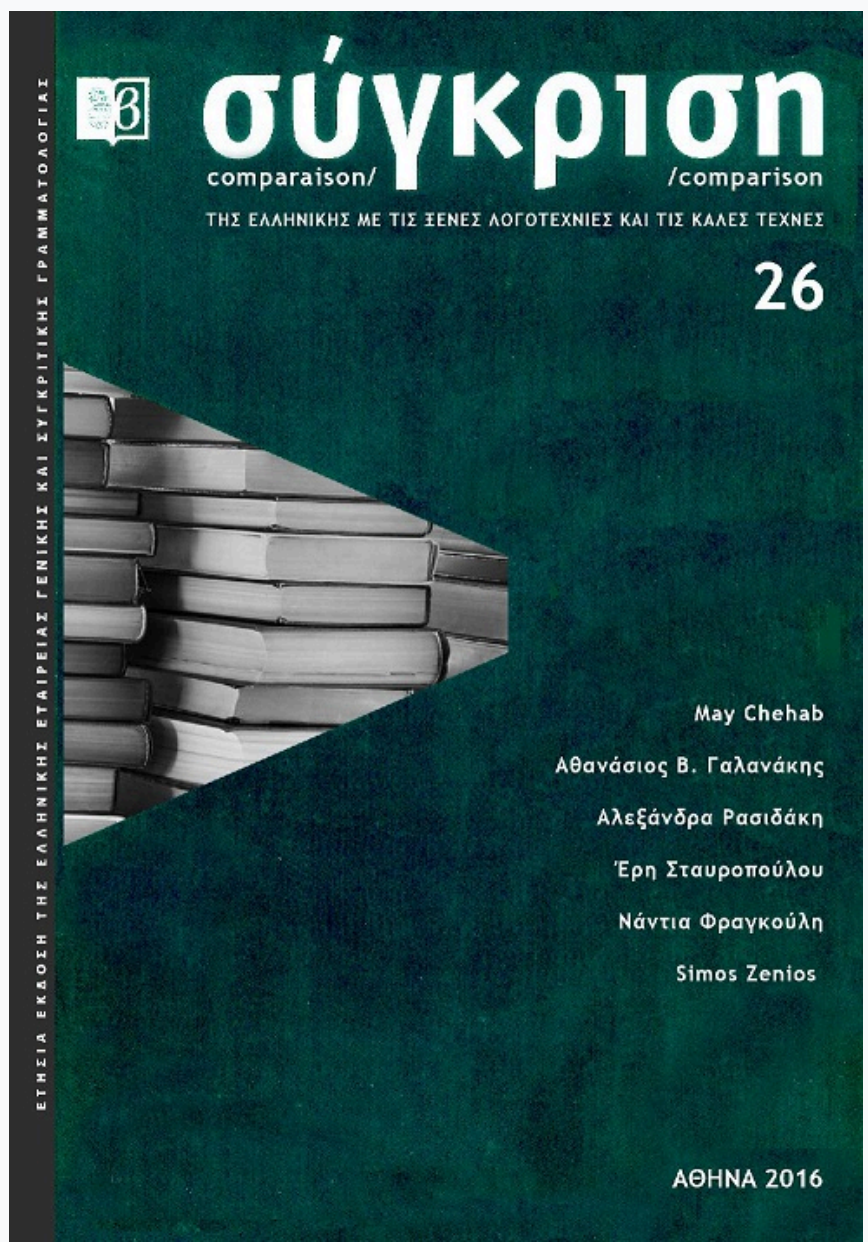

Mayotte BOLLACK (2017), Démons et dragons. Dixneuf pièces d'Euripide racontées et interprétées.

Paris : Arthème Fayard (coll. " ouvertures »), 201 p.

May Chehab

doi: $\underline{10.12681 / \text { comparison.16009 }}$

Copyright $\odot$ 2018, May Chehab

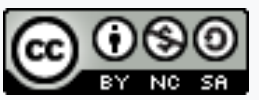

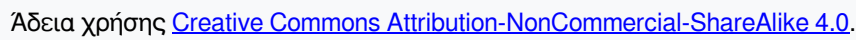

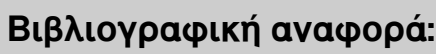

Chehab, M. (2018). Mayotte BOLLACK (2017), Démons et dragons. Dix-neuf pièces d'Euripide racontées et

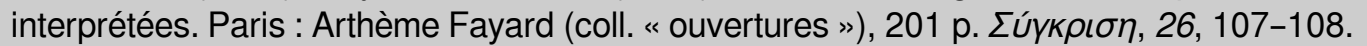

https://doi.org/10.12681/comparison.16009 


\section{Mayotte BOLLACK (2017), Démons et dragons. Dix-neuf pièces d'Euripide racontées et interprétées. Paris : Arthème Fayard (coll. « ouvertures »), 201 p.}

Seule une érudite de haute volée telle que Mayotte Bollack aurait pu de manière aussi remarquable relever le défi : raconter -le verbe illustrant la transposition n'est pas choisi au hasard- dix-neuf pièces d'Euripide en recevant l'esprit de l'original dans une langue de l'extrême contemporain et en inscrivant le commentaire herméneutique dans la fluidité du récit.

La forme elle-même de l'ouvrage atteste le parti de raccorder les Anciens à l'avenir de leur réactualisation. Chacune des dix-neuf pièces -en suite alphabétique, comme dans le recueil antique qui nous les a léguées- s'inscrit dans un même canevas : titre français consacré/translittération; bref sous-titre condensateur et parlant: Iphigénie en Tauride, qui suit Iphigénie à Aulis, a pour sous-titre «Vingt ans après »; Ion, «Le droit du sang»; Électre, un surprenant «Petits meurtres à la campagne » à la manière de l'auteur le plus traduit dans le monde ; Les Héraclides, "Le droit des réfugiés». Puis viennent, honorés dans leur forme et langue originales, les trois ou quatre premiers vers du texte d'Euripide : l'incipit de la pièce, suivi de sa traduction française, nous font glisser du théâtre grec à sa paraphrase française. Enfin, à la manière des morales d'apologues, une laconique conclusion offre au lecteur la substantifique moelle: ici, ce seront des vers tirés de la pièce même; là, une maxime épicurienne ou un proverbe devenu français ; ailleurs un vers de Kipling.

C'est que Mayotte Bollack, pour faire entendre aujourd'hui la " voix intérieure » d'Euripide (Préface, p. 8), puise en éclectique dans notre culture, qui est libre, et plurielle dans le temps et dans l'espace. Nul complexe franchouillard ne lui interdit d'expliciter la honte de Phèdre par un («shame», p. 95) bien anglais, nul fétichisme de registre ne l'empêche de faire dire aux Satyres qu'Hélène est une "putain » (p. 47), ni de présenter Oreste comme un «ex» (p. 29) d'Hermione. Non que la science ne soit pas là, avec la maitrise des textes en premier : elle est subtilement diluée dans le texte, avec ces fines évocations des étymologies des noms propres -vraies ou fausses, peu importe- si chères aux Grecs (Hippolyte « dont le nom disait qu'il déliait leurs liens», p. 99) ; Hélène la «tueuse d'hommes » dont le nom est «transcrit dans ses lettres fatales : 'celle qui prend' (helein)», p. 77); ou bien avec l'habile analogie entre l'autochtonie d'hier et celle d'aujourd'hui: «on était autochtone, c'est-à-dire 'né sur place', comme aujourd'hui on est du cru ou de souche » (p.103); ou encore, plus techniquement, avec le maintien des deux obèles (††) entourant une partie du texte grec d'Ion (p.101) pour un passage incertain ou contesté, suivant l'usage de la critique textuelle, même si c'est surtout dans l'appareil de notes placé à la fin des textes que se déroule le dialogue scientifique. Outre la philologie (ou 'herméneutique critique' selon Jean Bollack), l'apport obligé de la psychanalyse alimente l'interprétation de ces fictions mythologiques, dont certaines expressions entrées dans la langue donnent quelque mesure : entre Agamemnon et Ménélas, "deux fois un désir s'est renversé » (p. 115) ; Andromaque pique Hermione au point sensible d'une "libido frustrée » (p. 27) ; et la Toison d'or? c'est un « objet fétiche» (p. 133). Enfin, le tour de force de 
Mayotte Bollack réside dans la richesse de la langue d'accueil, non dépouillée de la culture qu'elle a créée et qui l'a générée : c'est tacitement, bien sûr, qu'elle rend hommage -et on peut ignorer ou savourer l'intertexte imité ou parodié- à Paul Valéry («L'intelligence n'est pas son fort», dit-elle pour décrire le roi Thoas, p. 127), ou à Montaigne et Rousseau lorsqu'elle décrit le mari d'Électre comme ayant «quelque chose du bon sauvage » (p. 54).

Des esprits chagrins, austères ou passéistes fronceront peut-être le sourcil devant les joyeux dyschronismes ("Le King Kong monstrueux à l'œil unique ») et la langue débridée de Mayotte Bollack (pour Héraclès, « le bonheur, bordel, il est dans l'instant»), mais pour l'immense majorité des lecteurs, lire Euripide en sa compagnie donnera une vie nouvelle à la visée ancienne. À lire, donc, et faire lire avec délectation, et à traduire, dans l'urgence.

May Chehab

University of Cyprus 
